\section{References}

1. World prison brief online database. Institute for Crime and Justice Policy Research website. https://www.prisonstudies.org/highest-to-lowest/occupancylevel?field_region_taxonomy_tid=Al. Published March 27, 2020. Accessed June 2, 2021.

2. Dolan, K, Wirtz AL, Moazen, B, et al. Global burden of HIV, viral hepatitis, and tuberculosis in prisoners and detainees. Lancet 2016;388: 1089-1102.

3. Prisons and the typhus/typhoid epidemic of 1908-1910: how the Russian imperial penal system contained the outbreak. Gulag Echoes website. https://blogs.helsinki.fi/gulagechoes/2020/05/19/prisons-and-thetyphus-typhoid-epidemic-of-1908-1910-how-the-russian-imperial-penalsystem-contained-the-outbreak/. Published May 19, 2020. Accessed June 6, 2021.

4. DR Congo: prisons face COVID-19 catastrophe. Human Right Watch Report website. https://www.hrw.org/news/2020/04/17/dr-congo-prisonsface-covid-19-catastrophe. Published April 17, 2020. Accessed June 15, 2021.
5. McAllister E, Kouagheu J. Coronavirus stalks cells of Cameroon's crowded prisons. Reuters website. https://www.reuters.com/article/us-healthcoronavirus-cameroon-prisons-i/coronavirus-stalks-cells-of-cameroonscrowded-prisons-idUSKBN24A0QZ. Published July 9, 2020. Accessed June 2, 2021.

6. Nearly 1,000 Russian federal prison authority's staff, over 200 inmates contract COVID-19. TASS Russian News Agency website. https://tass.com/ society/1160071. Published May 25, 2020. Accessed June 15, 2021.

7. Deaths in Brazilian prisons increased by $33 \%$ during the COVID-19 pandemic but only four were tied to the deadly virus. Daily Mail website. https://www.dailymail.co.uk/news/article-8348507/Brazil-prison-deathsincrease-33-percent-COVID-19-pandemic-four-tied-virus.html. Published May 22, 2020. Accessed June 2, 2021.

8. Hawks L, Woolhandler S, McCormick D. COVID-19 in prisons and jails in the United States. JAMA Intern Med 2020;180:1041-1042.

9. Coronavirus: healthcare and human rights of people in prison. Penal Re form International website. www.penalreform.org/resource/coronavirushealthcare-and-humanrights-of-people-in. Published 2020. Accessed May 4, 2020.

\title{
Finding a needle in a haystack: The hidden costs of asymptomatic testing in a low incidence setting
}

\author{
Vinay Srinivasan $\mathrm{MPH}^{1}$, Shruti K. Gohil MD², Shira R. Abeles MD², Deborah S. Yokoe MD', Stuart H. Cohen $\mathrm{MD}^{5}$, \\ Lynn Ramirez-Avila $M D^{6}$, Kavitha K. Prabaker $M D^{7}$ and Annabelle M. de St. Maurice $M D^{8}$ (i) \\ ${ }^{1}$ David Geffen School of Medicine, University of California Los Angeles, Los Angeles, California, ${ }^{2}$ Division of Infectious Diseases, Department of Medicine, \\ University of California San Diego School of Medicine, San Diego, California, ${ }^{3}$ Division of Infectious Diseases, Department of Medicine, University of California \\ Irvine, Irvine, California, ${ }^{4}$ Division of Infectious Diseases, Department of Medicine, University of California San Francisco, San Francisco, California, ${ }^{5}$ Division of \\ Infectious Diseases, Department of Medicine, University of California Davis, Sacramento, California, ${ }^{6}$ Division of Pediatric Infectious Diseases and Global Health, \\ Department of Pediatrics, University of California San Francisco, San Francisco, California, ${ }^{7}$ Division of Infectious Diseases, Department of Medicine, David Geffen \\ School of Medicine, University of California Los Angeles, Los Angeles, California and ${ }^{8}$ Division of Infectious Diseases, Department of Pediatrics, David Geffen \\ School of Medicine, University of California Los Angeles, Los Angeles, California
}

To the Editor-Early in the coronavirus disease 2019 (COVID-19) pandemic, when testing was limited and the prevalence of severe acute respiratory coronavirus virus 2 (SARS-CoV-2) was unknown, public health recommendations restricted testing for individuals at high risk for COVID-19. Risk factors included travel history, symptoms, and close contact with someone who had a history of COVID19. As access to testing expanded and concerns for asymptomatic transmission mounted, healthcare facilities broadened COVID-19 surveillance strategies to include testing for all asymptomatic patients requiring hospital admission or aerosol-generating procedures.

Simultaneously, national and global PPE shortages amplified concerns about high risks for to healthcare providers (HCPs). Initial studies reported infection from patients as the primary mode of transmission in up to $60 \%$ of COVID-19 infections in healthcare workers before the pandemic was recognized. ${ }^{1}$ Since that time, significant advances in testing capacity and PPE availability have been made, coupled with reassurance about the protective effects of PPE. ${ }^{2}$ Rates of COVID-19 positivity among asymptomatic patients presenting for surgery have been low

Author for correspondence: Annabelle de St. Maurice, Email: adestmaurice@mednet. ucla.edu

Cite this article: Srinivasan V, et al. (2022). Finding a needle in a haystack: The hidden costs of asymptomatic testing in a low incidence setting. Infection Control \& Hospital Epidemiology, 43: 1525-1526, https://doi.org/10.1017/ice.2021.288 throughout the pandemic: only $0.13 \%$ at an academic facility centered in one of the counties with the highest COVID-19 prevalence nationally. The total number of tests collected for asymptomatic surgical patients has exceeded 100,000 in the past 12 months. ${ }^{3,4}$ Data collected during this pandemic have demonstrated that healthcare workers are unlikely to become infected with COVID-19 when wearing appropriate PPE. ${ }^{2}$ Even in situations in which healthcare providers were performing an aerosol-generating procedure on a COVID-19-positive patient, the risk among those wearing a surgical mask and a respirator was equivalent. ${ }^{5}$ As PPE supply has increased in the United States, many healthcare institutions have begun using respirators and eye protection for all aerosol-generating procedures regardless of a patient's SARS-CoV-2 status, further decreasing the risk of unanticipated SARS-CoV-2 transmission.

Furthermore, as the incidence of a disease declines, the positive predictive value (PPV) of a test for that disease necessarily drops, even for tests with a high sensitivity and specificity. At low prevalence, the positive predictive value (PPV) of a given test is expected to be more sensitive to changes in underlying rates of disease. To illustrate this, we modeled the relationship between 7-day cumulative incidence of COVID-19 in the community ( $\mathrm{x}$-axis) and PPV (y-axis) for a PCR test with similar performance characteristics to those used at UCLA Health (ie, 96\% sensitivity and 99\% specificity), 


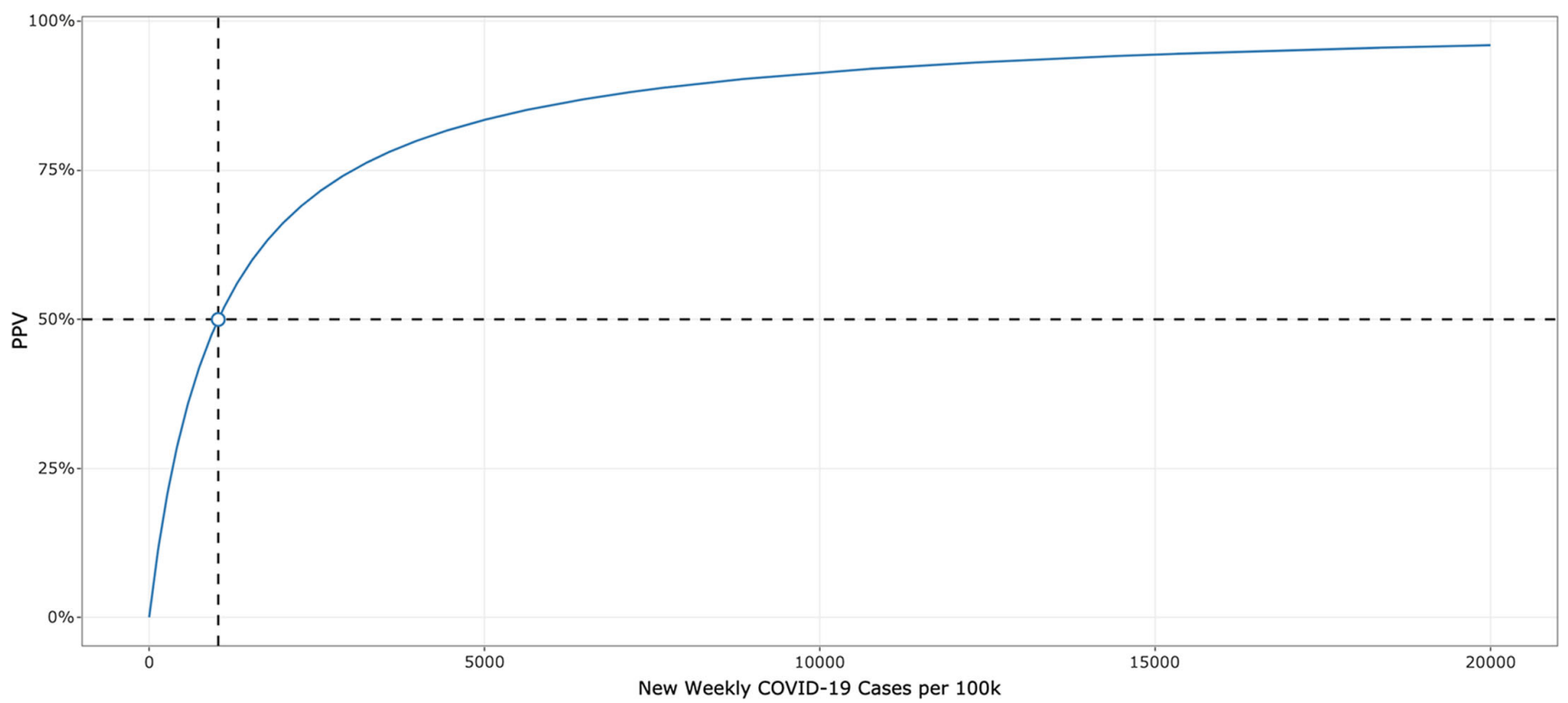

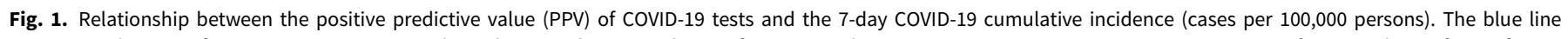
represents the PPV of a COVID-19 PCR test as the 7-day cumulative incidence of COVID-19 changes in a community, assuming a sensitivity of $96 \%$ and specificity of $99 \%$. The dashed line represents the point at which the PPV is $50 \%$.

assuming a weekly testing strategy (Fig. 1). We show that false positives exceed the number of true positives when 7-day cumulative COVID-19 incidence is below 1,030 cases per 100,000 persons. These false positives can delay care, can cause unnecessary hospital and community-setting quarantines, and can lead to repeated retesting. In addition, direct and indirect costs accrue with testing asymptomatic individuals at low risk of having COVID-19. First, COVID19 assays require expensive machines, reagents, and technologists' labor. According to a recent Kaiser Family Foundation survey of 93 hospitals, the median cost of a COVID-19 test was $\$ 148$. $^{6}$ Additional labor and supply expenses are incurred by clinics and hospitals running COVID-19 testing sites for preoperative patients.

The highest 7-day average of COVID-19 cases in the United States was 533 of 100,000 in January $2020^{6}$; however, rates varied substantially by locality. Currently, the 7-day average incidence is 13.65 of 100,000 in Los Angeles County and 48.95 of 100,000 nationally, ${ }^{7}$ with continued steady declines every day, suggesting that at this juncture in the US COVID-19 pandemic, the risk of false-positive tests and their associated consequences far outweigh the benefits of mass COVID-19 testing. The justification for maintaining such time and resource-intensive surveillance programs becomes more complex in the context of widespread use of highly effective vaccines in healthcare providers. It is time to rethink the strategy of testing asymptomatic individuals entering hospitals or receiving procedures.

Acknowledgments.

Financial support. No financial support was provided relevant to this article.
Conflicts of interest. All authors report no conflicts of interest relevant to this article.

\section{References}

1. Lai X, Wang M, Qin C, et al. Coronavirus disease 2019 (COVID-2019) infection among healthcare workers and implications for prevention measures in a tertiary hospital in Wuhan, China. JAMA Network Open 2020;3: e209666.

2. Jacob JT, Baker JM, Fridkin SK, et al. Risk factors associated with SARSCoV-2 seropositivity among US healthcare personnel. JAMA Network Open 2021;4:e211283.

3. Singer JS, Cheng EM, Murad DA, et al. Low prevalence (0.13\%) of COVID-19 infection in asymptomatic pre-operative/pre-procedure patients at a large, academic medical center informs approaches to perioperative care. Surgery 2020;168:980-986.

4. Lentz RJ, Colt H, Chen H, et al. Assessing coronavirus disease 2019 (COVID-19) transmission to healthcare personnel: the global ACT-HCP case-control study. Infect Control Hosp Epidemiol 2021;42:381-387.

5. Shah VP, Breeher LE, Hainy CM, Swift MD. Evaluation of healthcare personnel exposures to patients with SARS-CoV-2 associated with personal protective equipment use. Infect Control Hosp Epidemiol 2021. doi: 10.1017/ ice.2021.219.

6. Kurani NP, Pollitz K, Cotliar D, Ramirez G, Cox C. COVID-19 test prices and payment policy. Health System Tracker website. https://www.health systemtracker.org/brief/covid-19-test-prices-and-payment-policy/\#: : text=Data\%20from\%2093\%20hospitals\%20with,with\%20a\%20median\% 20of\%20\%24148. Published 2021. Accessed May 25, 2021.

7. COVID Data Tracker. Centers for Disease Control and Prevention website. https://covid.cdc.gov/covid-data-tracker/\#trends_dailytrendscases. Published 2021. Accessed May 25, 2021. 